\title{
Survival rates and causes of death in Vietnamese chronic hemodialysis patients
}

\author{
Bach Nguyen $^{1 *}$ and Fumiko Fukuuchi ${ }^{2}$
}

\begin{abstract}
Background: Thirty years have passed since hemodialysis therapy first started in Vietnam. However, there have been no reports on information such as the survival rate, mortality, and cause of death of hemodialysis patients on a national level. The aim of this study is to retrospectively analyze the data on hemodialysis patients from the flagship hospital in Ho Chi Minh City and to shed light on the status of hemodialysis patients in Vietnam.

Methods: The patients in this report were all 18 years or older who underwent hemodialysis at the Thong Nhat Hospital between April 1997 and December 2014. There were a total of 349 patients, with 225 males and 124 females. Data was collected on the age, sex, primary causes of end-stage renal diseases, starting date of hemodialysis, vascular access, hemodialysis therapy prescription, hemodialysis dose, coexisting conditions, clinical test data, and cause of death. IBM's statistical analysis software SPSS Statistics 23.0 was used.

Results: The survival time after hemodialysis introduction was $5.27 \pm 0.31$ years (mean \pm standard deviation). The factors which impacted the survival rate included being 60 years of age or older at the initiation of hemodialysis, being male, coexisting conditions, and vascular access apart from an artery venous fistula. The prognosis of diabetic patients suffering from renal failure was poor when compared to that of patients without diabetes; however, there was no statistical significance. The most common cause of death was cardiovascular disease (46.1\%), followed by other causes (11.8\%) and unknown causes (23.6\%).

Conclusions: Our data shows that mean survival time was shorter than that in other countries. One-year and 5-year survival rates were not so different. However, a 10-year survival rate was very low. Significant risk factors were not so special, but we have a problem in medical cost in Vietnam. To improve the long-term survival rate, we are trying to change the situation.
\end{abstract}

Keywords: Survival rate, Maintenance hemodialysis, Vietnamese adults

\section{Background}

There is no national data available for the survival rate and cause of death in hemodialysis patients in Vietnam. While this data is only for a single hospital, we hope to gain an understanding of the situation regarding hemodialysis patients in Vietnam and we started with this investigation.

There are aspects with the hemodialysis patients in Vietnam that are different from those in other countries. First, the starting point for hemodialysis therapy is delayed. There is a tendency to prolong the starting point of hemodialysis as long as possible. The

\footnotetext{
* Correspondence: nguyenbach69@gmail.com

'Department of Nephrology and Dialysis, Thong Nhat Hospital, 01 Ly Thuong

Kiet Street, Tan Binh Dist, Ho Chi Minh City, Vietnam

Full list of author information is available at the end of the article
}

economic situation also plays a role in this tendency. The cost of one session of hemodialysis is US $\$ 20$, which is cheap when compared to that in other countries. Note that the government's health insurance generally covers the reuse of a dialyzer for up to six times. If a patient wishes to extend the treatment further, the patient must pay for the expense himself or herself. There is also an insurance system that provides assistance for the poor; however, there is not enough money to introduce hemodialysis. Hemodialysis is only used when patient's circumstances take a turn for the worse including increased risk and the situation calls for it. In addition, there is also a variance in the proportion of diseases similar to other Asian countries. The Doi Moi Policy 
introduced economic reforms in 1986, and the number of infections decreased, which had previously accounted for more than $50 \%$ of all deaths. This figure dropped to below $20 \%$ in 2005. On the other hand, a change in lifestyle most likely caused an increase in circulatory diseases and diabetes. The number of deaths caused by non-infectious diseases, including malignant neoplasms or growths, exceeds $62 \%$.

Based on this medical data and the conditions in Vietnam, we shall perform an analysis on the survival rate and cause of death in hemodialysis patients.

\section{Methods}

\section{Patients}

All patients in this study were 18 years or older who underwent hemodialysis at the Thong Nhat Hospital between April 1997 and December 2014. This is the first class, governmental, and teaching hospital with 700 beds in 1997 and upgraded 1200 beds in 2014 . There were only 10 hemodialysis machines sponsored by a Japanese donor in 1997 and increased to 25 machines in 2014. Hemodialysis center is open $24 \mathrm{~h}$ per day with four sections and serves around 360 new patients annually. Some of stable patients were transferred back to provincial hospitals around Ho Chi Minh City for chronic hemodialysis.

All patients included in this study met the following conditions: (1) patients who received the appropriate hemodialysis prescription (the standard for hemodialysis was $k t / v>1.2$ ), (2) patients who underwent hemodialysis for more than 1 month, and (3) patients that have all patient data available. The following patients were excluded: (1) cases in which the patient could have suffered from acute kidney injury or could have withdrawn from hemodialysis therapy and (2) patients who are undergoing or underwent hemodialysis at other hospitals.

The standard for introducing hemodialysis therapy to patients was a creatinine clearance that is less than $10 \mathrm{~mL} / \mathrm{min}$ for non-diabetic patients and a creatinine clearance of $15 \mathrm{~mL} / \mathrm{min}$ for diabetic patients. In terms of the hemodialysis conditions, a bicarbonate dialysate was used, and the dialysate flow rate was $500 \mathrm{~mL} / \mathrm{min}$. The blood flow rate $(\mathrm{mL} / \mathrm{min})$ was $5 \times$ DW (dry weight) and $250-300 \mathrm{~mL} / \mathrm{min}$ in average. A standard heparin was used as an anticoagulant. All the patients were dialyzed three times per week, and the average duration per dialysis session was $4 \mathrm{~h}$ with Nipro and Nikkiso Machines. The dialyzer was selected based on the financial status of the patient. The dialyzer was reused on average up to six times. The target hemoglobin level for anemia treatment was $10 \mathrm{~g} / \mathrm{dL}$ or greater.
Coexisting conditions included cardiovascular diseases (myocardial infarction, congestive heart failure, atherosclerosis, cerebrovascular accident, cardiac arrhythmia, and thoracic or abdominal artery aneurysm), cirrhosis, malignant tumors, tuberculosis, gastric ulcers, malnutrition, cognitive disorders, hematologic diseases, and chronic obstructive pulmonary disease. The causes of death were divided into six categories: (1) myocardial infarction, (2) heart failure, (3) infections, (4) stroke, (5) others, and (6) unknown cause of death.

Table 1 Baseline characteristics of the chronic hemodialysis patients $(n=349)$

\begin{tabular}{|c|c|}
\hline Baseline characteristics of the patients & $\begin{array}{l}\text { Number of } \\
\text { patient (\%) }\end{array}$ \\
\hline Age at the initiation of hemodialysis ( $\bar{X} \pm \mathrm{SD}$, years) & $\begin{array}{l}65.24 \pm 12.56 \\
(22-96)\end{array}$ \\
\hline \multicolumn{2}{|l|}{ Age group at the start of hemodialysis } \\
\hline$<60$ & $85(24.4)$ \\
\hline $60-69$ & $129(37)$ \\
\hline $70-79$ & $97(27.8)$ \\
\hline$\geq 80$ & $38(77.55)$ \\
\hline Male & $225(64.5)$ \\
\hline \multicolumn{2}{|l|}{ Primary causes of end-stage renal disease } \\
\hline Diabetes & $153(43.8)$ \\
\hline Hypertension & $109(31.2)$ \\
\hline Chronic glomerulonephritis & $35(10)$ \\
\hline Unknown & $52(14.9)$ \\
\hline Coexisting conditions & $180(51.6)$ \\
\hline Cardiovascular diseases $^{a}$ & $109(31.2)$ \\
\hline Tuberculosis & $10(3.72)$ \\
\hline Liver cirrhosis & $20(5.73)$ \\
\hline Dementia & $19(5.44)$ \\
\hline Malignancy & $15(4.29)$ \\
\hline Chronic obstructive pulmonary disease & $7(2.01)$ \\
\hline Serum albumin $\geq 35 \mathrm{~g} / \mathrm{dL}$ & $279(79.94)$ \\
\hline Erythropoietin use (subcutaneous route) & $349(100)$ \\
\hline Hemoglobin $\geq 10 \mathrm{~g} / \mathrm{dL}$ & $198(56.73)$ \\
\hline $\begin{array}{l}\text { The initiation of chronic hemodialysis } \\
\text { with sudden change }\end{array}$ & $330(94.56)$ \\
\hline Hemodialyzed by a high-flux dialyzer & $192(55.01)$ \\
\hline Reuse of a dialyzer & $324(92.84)$ \\
\hline \multicolumn{2}{|l|}{ Follow-up period of patients (month) } \\
\hline Median (25-75\%) & $25(10-51.5)$ \\
\hline Minimum-maximum & $1-172$ \\
\hline
\end{tabular}

${ }^{a}$ Cardiovascular diseases (myocardial infarction, congestive heart failure, cerebrovascular accident, arrhythmia, thoracic or abdominal artery aneurysm, and coronary artery diseases) 


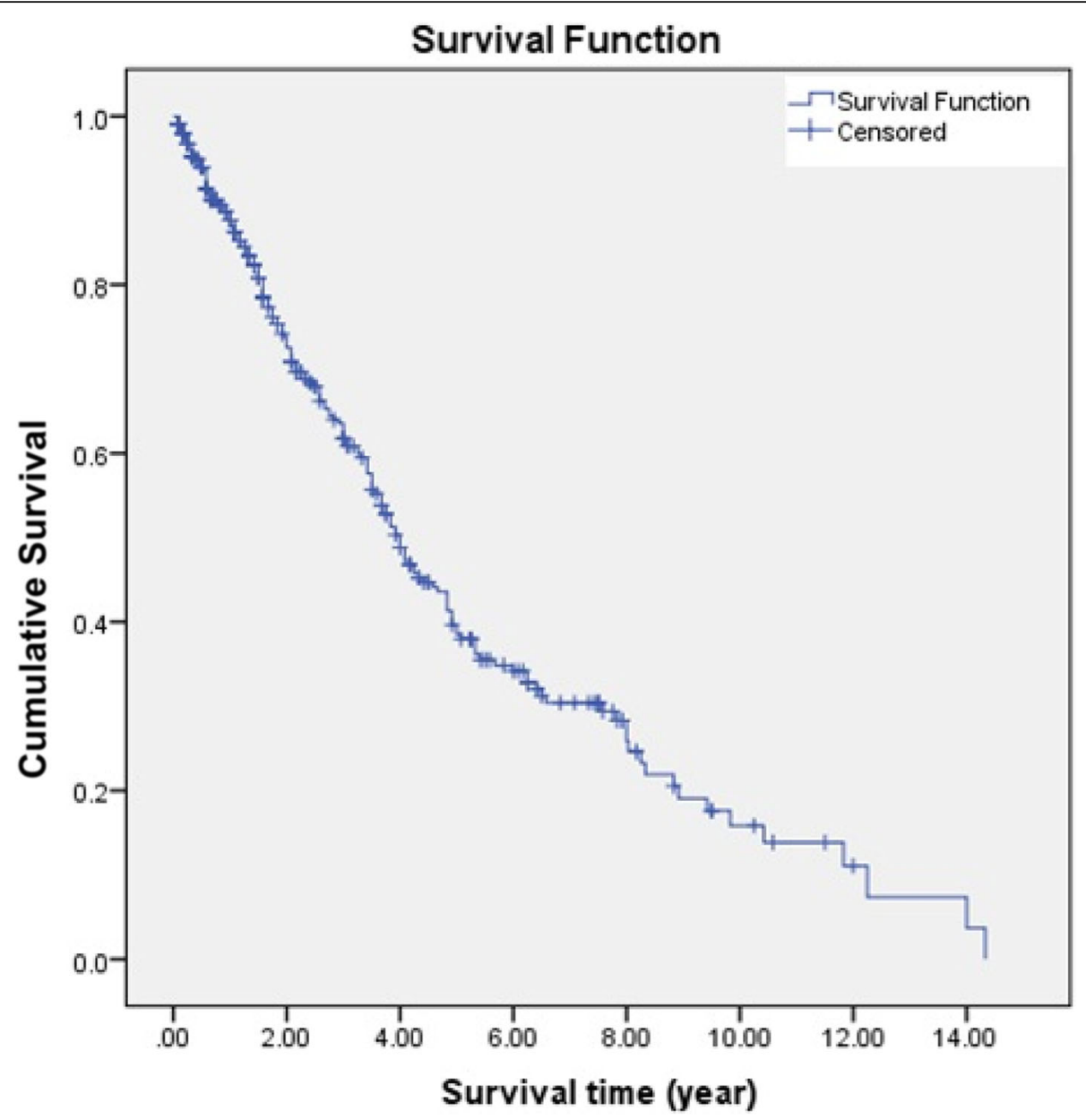

Fig. 1 Kaplan-Meier survival curves of chronic hemodialysis

\section{Methods}

This was a retrospective, observational study to evaluate the survival rate and causes of death in chronic hemodialysis patients at the Thong Nhat Hospital.

\section{Statistical analysis}

IBM's statistical analysis software SPSS Statistics 23.0 was used. The percentage and mean \pm SD of the mean were used to describe categorical and continuous variables, respectively. The Kaplan-Meier method was used to calculate the cumulative survival rate, and the log-rank test, for extracting the factors that impacted the survival rate, was used to examine the data. In addition, the Cox proportional hazards model or regression analysis was used to calculate the hazard rate. For univariate analysis, a cross tabulation was created for one factor/variable and a chi-squared $\left(x^{2}\right)$ test was performed. Any factor that was determined significant in the univariate analysis was used in the multivariate analysis. In the two-tailed test, the statistical significance was computed as $p<0.05$.
Table 2 Factors affecting survival time

\begin{tabular}{|c|c|c|c|}
\hline Factors & Mean survival time (year) & $x^{2 a}$ & $p$ \\
\hline \multicolumn{4}{|l|}{$\begin{array}{l}\text { Age group at the initiation } \\
\text { of hemodialysis }\end{array}$} \\
\hline$\geq 60$ & 3.64 & 11.496 & 0.0007 \\
\hline$<60$ & 8.27 & & \\
\hline \multicolumn{4}{|l|}{$\begin{array}{l}\text { End-stage renal disease } \\
\text { caused by diabetes }\end{array}$} \\
\hline Yes & 3.53 & 2.754 & 0.097 \\
\hline No & 4.62 & & \\
\hline \multicolumn{4}{|l|}{ Sex } \\
\hline Male & 3.74 & 4.821 & 0.028 \\
\hline Female & 5.07 & & \\
\hline \multicolumn{4}{|l|}{ Coexisting conditions } \\
\hline Yes & 3.37 & 13.896 & 0.0002 \\
\hline No & 6.01 & & \\
\hline \multicolumn{4}{|l|}{ Vascular access } \\
\hline Arteriovenous fistula & 4.47 & 87.10 & 0.0032 \\
\hline $\begin{array}{l}\text { Arteriovenous graft, tunnel } \\
\text { permanent catheter }\end{array}$ & 2.82 & & \\
\hline
\end{tabular}




\section{Results}

Table 1 shows the patient background or baseline characteristics. The total number of patients was 349 . The average age at the initiation of hemodialysis was $65.25 \pm 12.56$ years (mean \pm standard deviation). There were 225 males and 124 females. Eighty-five patients (24.4\%) started hemodialysis before 60 years of age. The most common primary disease was diabetes, found in $43.8 \%$ of the patients. Chronic glomerulonephritis was found in $10 \%$ of the patients. The primary disease was unknown in $14.9 \%$ of the patients. The introduction of hemodialysis due to a sudden change in the patient's condition occurred in $94.56 \%$ of the patients. These patients were admitted to the hospital because of acute complications of ESRD such as pulmonary edema, hyperkalemia, severe metabolic acidosis, and severe congestive heart failure. The introduction of hemodialysis was scheduled or planned for only 19 patients (5.44\%). The poor management of chronic kidney diseases in primary health care system is responsible for this problem. Coexisting conditions were found in $51.6 \%$ of the patients, and the most common coexisting conditions were cardiovascular complications, existing in $31.2 \%$ of the patients. Erythropoietin is generally administered as a subcutaneous injection. A high-flux dialyzer was used in $55.01 \%$ of the patients and was only single use in $7.16 \%$ of the patients. The average follow-up time was 25 months.

Figure 1 shows the cumulative survival rate for all the patients. The average survival time is $5.27 \pm 0.31$ years (mean \pm standard deviation). Eighty-five percent of the patients had a 1 -year survival rate, $58 \%$ had a 5 -year survival rate, and $20 \%$ had a 10 -year survival rate. The cumulative survival rate calculated using the Kaplan-Meier method is displayed according to each factor, and the log-rank test is used to compare those factors (Table 2). First, the patients were compared dividing the age at the initiation of hemodialysis into two groups (Fig. 2): under 60 years old and 60 years of age or older. There was a significant decrease in the survival rate for the 60 years of age and older group.

After comparing the survival times between the diabetic patients and the non-diabetic patients, the non-diabetic patient group had an average survival time of $5.71 \pm 0.41$ years

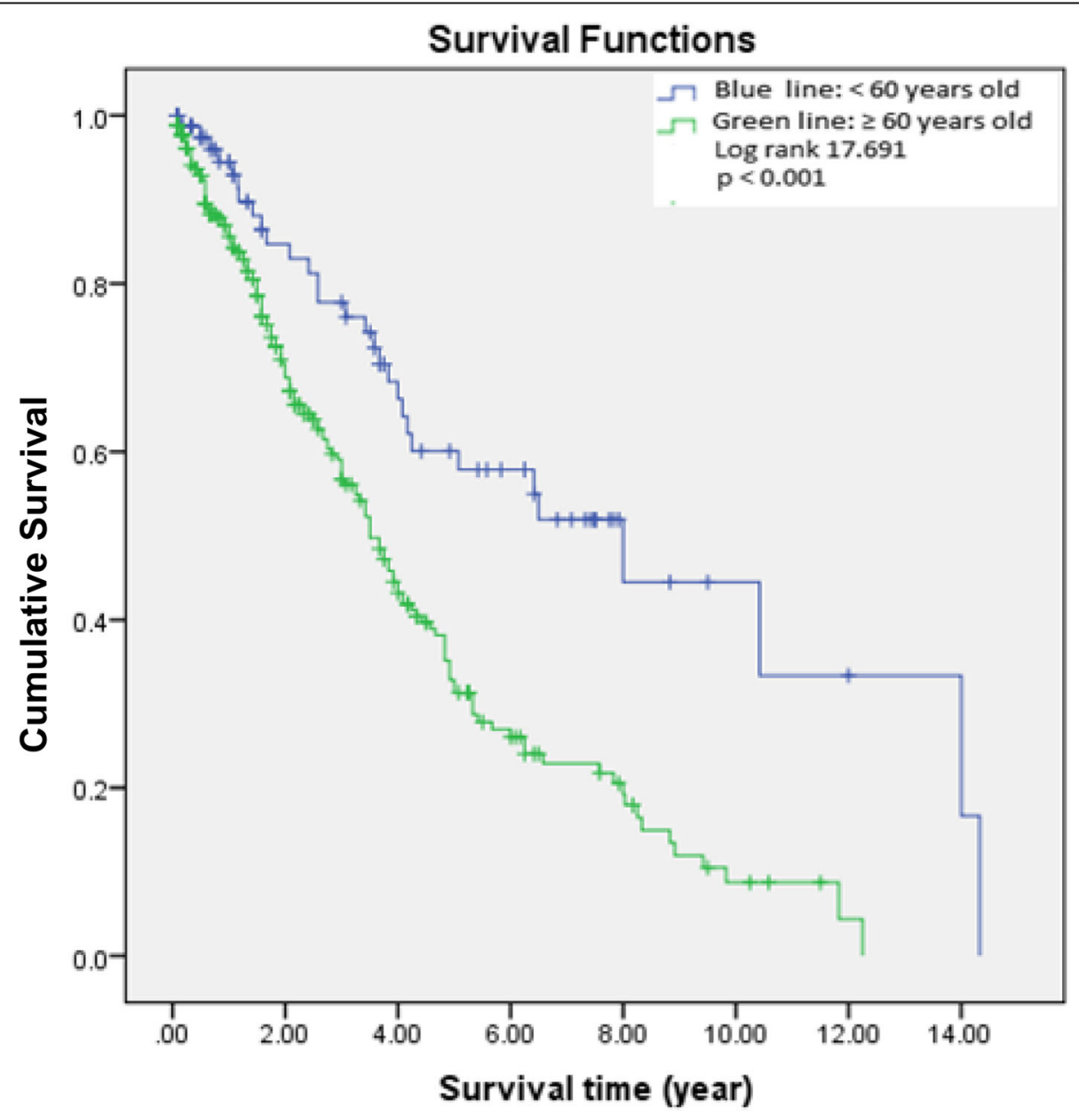

Fig. 2 Factor (60 years of age or older at initiation of hemodialysis) added to Kaplan-Meier and log-rank test 
(mean \pm standard deviation), and the diabetic patient group had an average survival time of $4.45 \pm 0.36$ years (Fig. 3). The diabetic patient group had a lower survival rate; however, there was no statistical significance. When comparing the males and females, the females had a significantly higher survival rate. The average survival time for males was $4.77 \pm 0.348$ years, and the average for females was $6.00 \pm 0.500$ years (Fig. 4). There was also a significant difference seen even between the patient group with coexisting conditions and the group without them. The survival time for the patient group with coexisting conditions was $6.91 \pm 0.598$ years, and it was $4.285 \pm 0.327$ years for the patient group without coexisting conditions (Fig. 5). In addition, there was a significant difference seen even with the vascular access. Compared to the patient group with an arteriovenous fistula, the patient group using an arteriovenous graft or tunnel permanent catheter had a significantly lower survival time (Fig. 6). A multivariate analysis was performed using a Cox proportional hazards model on those factors that showed a significant difference. The vascular access problems affected the survival rate with a hazard rate of 1.395. The survival curve for the covariate average values approaches the survival curve computed using the KaplanMeier method (Table 3). In the cause of death analysis, cardiovascular deaths were the most common at $46.1 \%$, and infections were next in line at $18.5 \%$. Cirrhosis, malignant tumors, tuberculosis, and traffic accident deaths all together accounted for $11.8 \%$. Unknown cause of death accounted for $23.6 \%$ (Table 4). The patients with an unknown cause of death were cases in which the patients died at home.

In a multivariate analysis using the Cox proportional hazards model, a univariate chi-squared $\left(x^{2}\right)$ test was performed on the three factors (sex, age at the initiation of hemodialysis, coexisting conditions) with a hazard rate of less than 1 and on the presence of diabetes. There was no significance with the presence of diabetes; however, being male, being 60 years of age or older at the initiation of hemodialysis, and having coexisting conditions had a significant impact on the survival time (Table 3). A logistic regression analysis was carried out using these factors. Patients having coexisting conditions had the most impact with a 3.174 odds ratio. Being male and being 60 years of

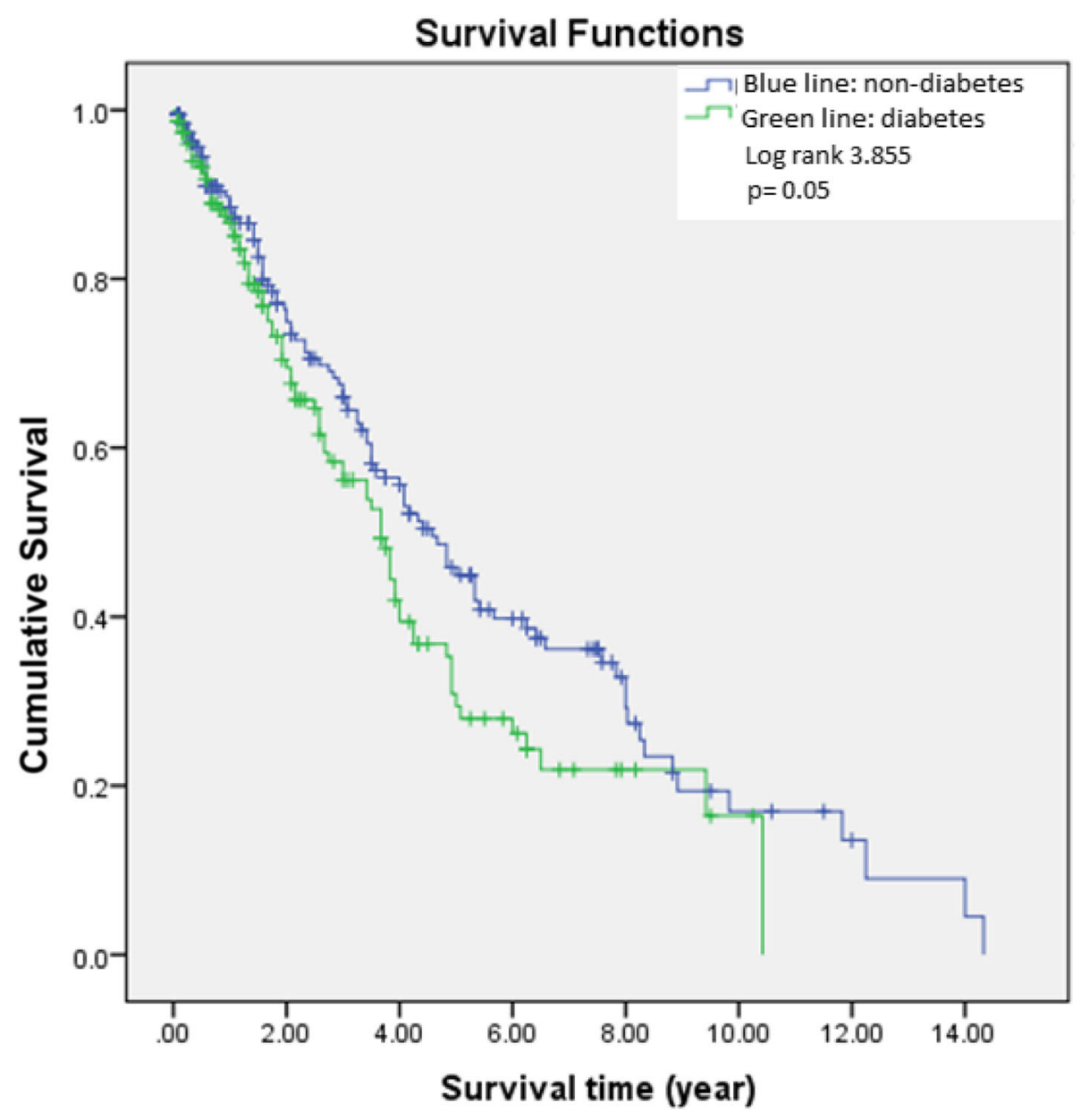

Fig. 3 Factors (primary disease and diabetic nephropathy) added to Kaplan-Meier and log-rank test 


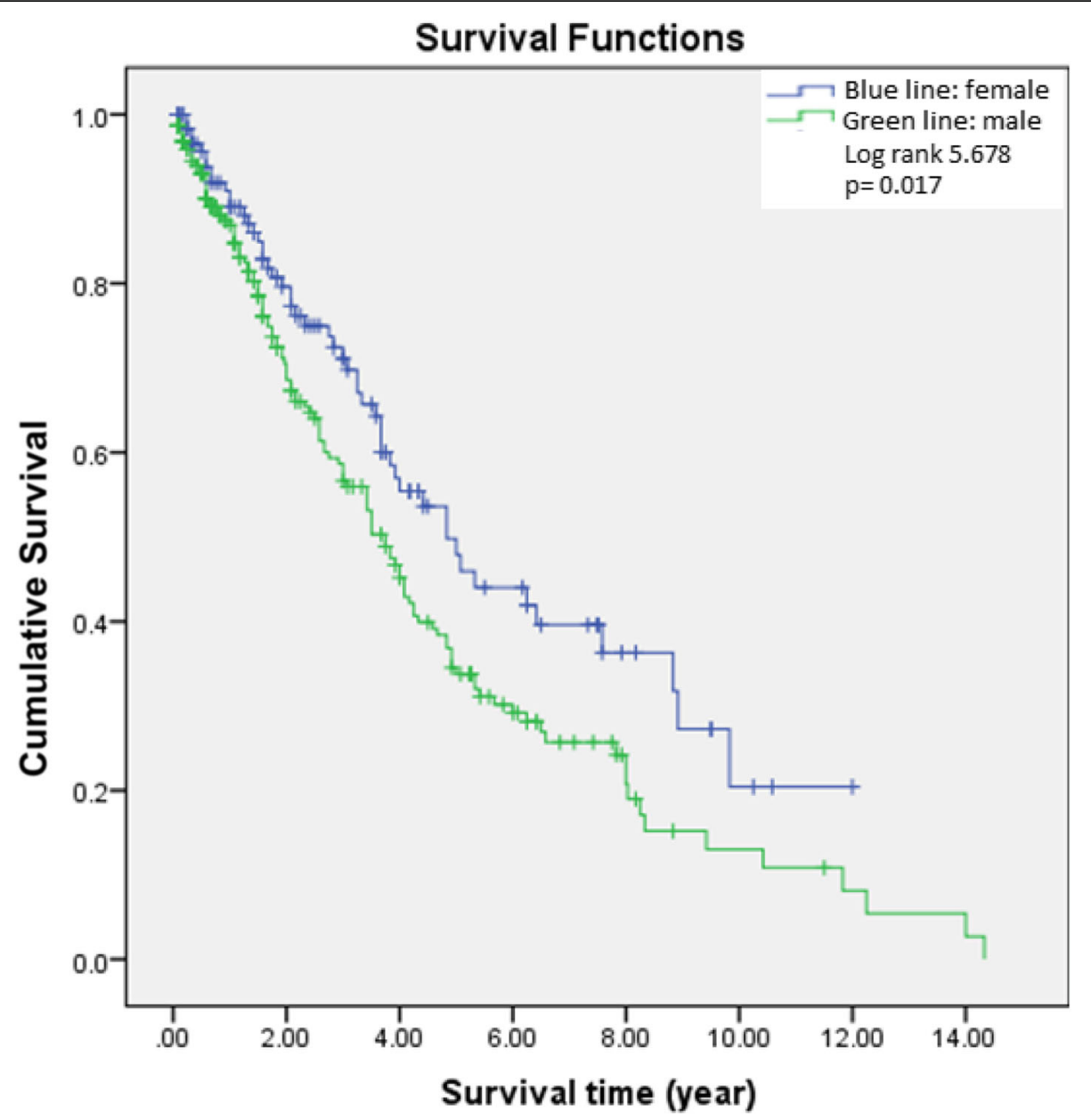

Fig. 4 Factor (sex) added to Kaplan-Meier and log-rank test

age or older at the initiation of hemodialysis also had significant impact on the survival rate (Tables 5 and 6).

\section{Discussion}

Our investigation results are the first statistics related to the survival rate of hemodialysis patients in Vietnam. The data is only from one hospital, and the total number of patients is low. However, there was little variation in the hemodialysis technique and prescription, and the therapy regimen could be followed, thereby also increasing the reliability.

The average survival time for hemodialysis patients in this study was $5.27 \pm 0.31$ years (mean \pm standard deviation). These time periods are short when compared to those in a report from the USA showing female patients with an average of 7.1 years and male patients with an average of 7.2 years [1]. With regard to the survival rate, $85 \%$ of the patients had a 1-year survival rate, $58 \%$ had a 5 -year survival rate, and $20 \%$ had a 10 -year survival rate. Survival time of our patients was better than that of Sawhney S et al. in British Columbia and Scotland [2] and Seyed
Seifollah Beladi Mousavi et al. in Iran [3]. There is variation in the survival rate of hemodialysis patients depending on the country, and the figures cannot be compared in simple terms. However, the annual statistics report by The Japanese Society for Dialysis Therapy shows $87.6 \%$ for a 1 year survival rate, $59.8 \%$ for a 5 -year survival rate, and $36.3 \%$ for a 10-year survival rate in 2013 [4]. In a report investigating the prognosis of hemodialysis patients in Japan by Iseki et al., the 1 -year survival rate was $87.4 \%$, the 5 -year survival rate was $60.9 \%$, and the 10 -year survival rate was $39.1 \%$ [5]. Korean data showed a 1-year survival rate of $94 \%$ and a 5 -year survival rate of $66 \%$ [6]. A report from England showed improvement between 1997 and 2006, with a change in the 1-year survival rate from 85.9 to $91.5 \%$. It also showed a rise in the survival rate for the elderly (65 years and older) from 63.8 to $72.9 \%$ [7]. Our investigation results are comparable to the data from these countries for the 1- and 5-year survival rates, but the 10year survival rate is lower. Improvements need to be made for the prognosis of hemodialysis patients with respect to long-term care. 


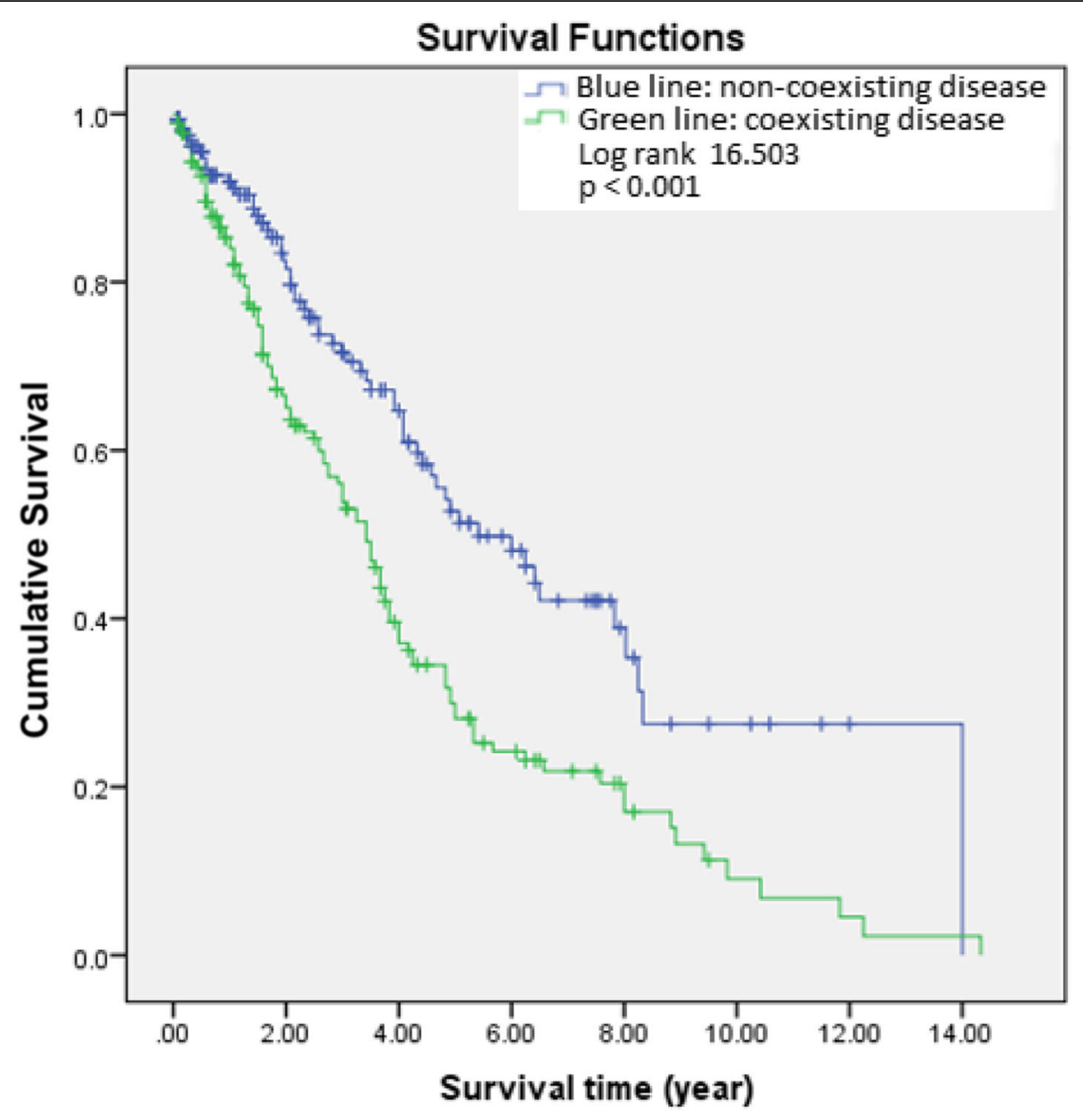

Fig. 5 Factor (coexisting conditions) added to Kaplan-Meier and log-rank test

Vascular access problems, being 60 years of age or older at the initiation of hemodialysis, being male, and having coexisting conditions were reported as factors that impact the survival rate. Using a catheter or arteriovenous graft can adversely impact the prognosis, which is consistent with other investigation results. Shunt clotting can be attributed to the impact from diabetes or arteriosclerosis $[8,9]$. Other investigations as well have indicated that female hemodialysis patients tend to have a better prognosis [1]. There were no new risk factors that were specifically identified in this investigation. As noted in the results from this investigation, the aging of patients at the initiation of hemodialysis is becoming a problem in other countries as well $[10,11]$. The report from England indicates that the age of patients at the initiation of hemodialysis greatly influences the prognosis. When comparing the 5-year survival rates, the survival rate is $70 \%$ for patients who are between 45 and 54 years old at the initiation of hemodialysis and only $30 \%$ when the patient is between 65 and 74 years old [12]. In addition, a report by Uchida et al. shows a 65\% 3-year survival rate for the patient group who have an age of $61.7 \pm 14.4$ years at the initiation of hemodialysis [13]. The average age at the initiation of hemodialysis for the patient groups of our investigation was $65.24 \pm 12.56$ years, with a 5-year survival rate of $58 \%$, but there is nothing that can really be done about this. Although it must be considered that almost hemodialysis introduction has been done in emergency in Vietnam, emergency hemodialysis introduction is very hard for old patients. We know that it is better to do planned hemodialysis introduction, but it is impossible in Vietnam now. It is caused by poor management of chronic kidney disease (CKD) and economical problem. It is very difficult for us to do adequate treatment in time. We are short of doctors and medical system to follow up CKD patients. We are trying better in the future.

Similarly, to other countries, the number one cause of death was cardiovascular death. After that, what is distinctive about our investigation is infections. Death caused by infection was primarily pneumonia-related. Even in Vietnam, the country is in a transitional phase, moving from developing status to developed status; the 


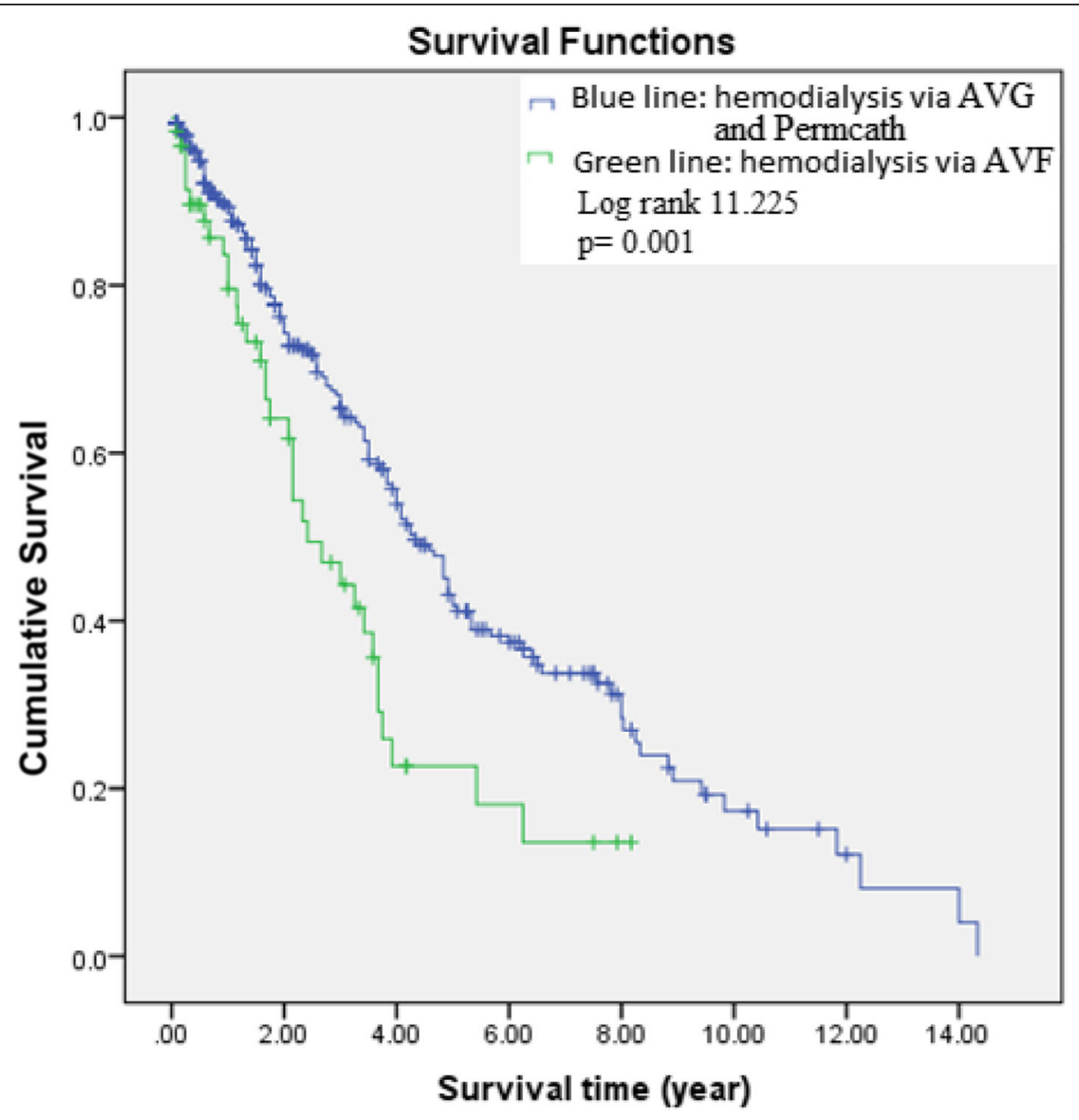

Fig. 6 Factor (vascular access) added to Kaplan-Meier and log-rank test

Table 3 Multivariate analysis: Cox proportional hazards model including factors predicting mortality

\begin{tabular}{llllllll}
\hline Factors & B & SE & $x^{2}$ & $p$ & $\begin{array}{l}\text { Hazard } \\
\text { ratio }\end{array}$ & $\begin{array}{l}\text { Cl 95\% } \\
\text { for HR }\end{array}$ \\
\hline $\begin{array}{l}\text { Age group at the } \\
\text { initiation of } \\
\text { hemodialysis } \geq 60\end{array}$ & -0.701 & 0.210 & 11.080 & 0.001 & 0.496 & $0.423-$ \\
Male & & & & & & 0.793 \\
& -0.545 & 0.176 & 9.626 & 0.002 & 0.580 & $0.411-$ \\
Coexisting conditions & -0.546 & 0.161 & 11.578 & 0.001 & 0.579 & $0.423-$ \\
& & & & & & 0.793 \\
$\begin{array}{l}\text { Vascular access via } \\
\text { arteriovenous graft, } \\
\text { tunnel permanent } \\
\text { catheter }\end{array}$ & -0.772 & 0.204 & 14.374 & $<0.001$ & 0.462 & $0.310-$ \\
\hline
\end{tabular}

Table 4 Causes of death $(n=178)$

\begin{tabular}{lll}
\hline Causes of death & Number of patient & Percentage (\%) \\
\hline Stroke & 43 & 24.2 \\
Heart failure & 28 & 15.7 \\
Myocardial infarction & 11 & 6.2 \\
Infections with etiologies from & 33 & 18.5 \\
$\quad$ Respiratory system & 16 & \\
$\quad$ Gastrology & 6 & \\
$\quad$ Urology & 3 & \\
$\quad$ Others & 8 & 11.8 \\
Other causes & \\
Unknown causes & 21 & 23.6
\end{tabular}

aLiver cirrhosis, malignancy, tuberculosis, and transportation accident 
Table 5 Univariate comparison of factors between patients alive and dead

\begin{tabular}{llll}
\hline Factors & Alive $(n=171)$ & Dead $(n=178)$ & $p$ \\
\hline Male, $n(\%)$ & $98(57.31)$ & $127(71.35)$ & 0.004 \\
$\begin{array}{l}\text { End-stage renal disease } \\
\text { caused by diabetes, } n(\%)\end{array}$ & $74(43.27)$ & $79(44.38)$ & 0.460 \\
$\begin{array}{l}\text { Age at the initiation of } \\
\text { hemodialysis }(\bar{X} \pm \text { SD) }\end{array}$ & $61.74 \pm 13.68$ & $68.61 \pm 10.12$ & $<0.001$ \\
$\begin{array}{l}\text { Age group at the initiation } \\
\text { of hemodialysis }\end{array}$ & & & \\
$\quad<60$ & $55(32.16)$ & $30(23.62)$ & \\
$60-69$ & $64(37.43)$ & $65(36.52)$ & 0.002 \\
$70-79$ & $39(22.81)$ & $58(32.58)$ & \\
$\geq 80$ & $13(7.6)$ & $27(15.16)$ & \\
Coexisting conditions, $n(\%)$ & $62(36.26)$ & $118(66.29)$ & $<0.001$ \\
\hline
\end{tabular}

diet has become more westernized. As a result, conditions attributed to lifestyle and diet as well as diabetic patients are also increasing. It is known that diabetic patients undergoing hemodialysis are more susceptible to infection. It is likely that improvements in the sanitary conditions in Vietnam have had a positive impact on the prognosis of hemodialysis patients.

We hope to see improvements not only in the sanitary conditions but in the current low-cost hemodialysis as well. The current cost of hemodialysis for a single session in Vietnam is approximately US\$20. In order to achieve this low cost, the dialyzer is reused up to six times. The same blood circuit or access is also reused depending on the circumstances. A high-flux dialyzer and single-use application can be effective for the prognosis of hemodialysis patients for long-term care, but it is quite difficult to achieve this immediately. However, we would like to strive toward making this a reality.

\section{Limitations to the study}

This study has several limitations like the lack of longitudinal data on all the risk factors such as serum calcium, phosphate, serum albumin, glucose control, lipid profile, and dialyzers, and causes of death might be incorrect, especially in dialysis patients who died at home.

Table 6 Multinominal logistic regression of factor predicting mortality

\begin{tabular}{lllllll}
\hline Factors & $B$ & SE & $x^{2}$ & $p$ & Hazard ratio & Cl 95\% for HR \\
\hline $\begin{array}{l}\text { Age } \geq 60 \\
\text { years old }\end{array}$ & -0.337 & 0.124 & 7.390 & 0.007 & 0.714 & $0.560-0.910$ \\
Male & -0.536 & 0.240 & 5.498 & 0.019 & 0.570 & $0.356-0.912$ \\
$\begin{array}{l}\text { Coexisting } \\
\text { conditions }\end{array}$ & -1.142 & 0.230 & 24.554 & $<0.001$ & 0.319 & $0.230-0.510$ \\
\hline
\end{tabular}

\section{Conclusions}

This is the first published statistics related to the survival rate of hemodialysis patients in Vietnam, although the data is only from one hospital. We hope this paper is useful to improve the long-term survival rate in hemodialysis patients in Vietnam.

\section{Abbreviations \\ AVF: Arteriovenous fistula; AVG: Arteriovenous graft; CHD: Chronic hemodialysis; ESRD: End-stage renal disease; HD: Hemodialysis; Permcath: Permanent catheter (tunnel permanent catheter)}

\section{Acknowledgements}

We thank the directors of the Thong Nhat Hospital, Prof Nguyen Manh Phan and Prof Nguyen Duc Cong for their encouragements, Ms Vu Thi Hoa and Ms Hua To Hoa for assisting us in collecting the data.

\section{Funding}

This study has not received any grants.

\section{Availability of data and materials}

Please contact author for data requests.

\section{Authors' contributions}

BN carried out the design of the study and collected the data. FF participated in the design of the study, performed the statistical analysis, and edited the draft. Both authors read and approved the final manuscript.

\section{Competing interests}

The authors declare that they have no competing interests.

\section{Ethics approval and consent to participate}

Thong Nhat Hospital Medical scientific committee number TN-13-06-1997. Patient consent: All patients provided written informed consent before inclusion.

All authors have approved the manuscript and agree with its submission to JSDT official journal Renal Replacement Therapy (RRT).

\section{Author details}

'Department of Nephrology and Dialysis, Thong Nhat Hospital, 01 Ly Thuong Kiet Street, Tan Binh Dist, Ho Chi Minh City, Vietnam. ${ }^{2}$ Department of Nephrology and Dialysis, Hayama Heart Center, Hayama, Japan.

Received: 23 August 2016 Accepted: 8 February 2017

Published online: 30 April 2017

\section{References}

1. United States Renal Data System. 2008 Annual Data Report. Am J Kidney Dis. 2009;53(1 Suppl):S1-374. doi:10.1053/j.ajkd.2008.10.005.

2. Sawhney S, Djurdjev O, Simpson K, et al. Survival and dialysis initiation: comparing British Columbia and Scotland registries. Nephrol Dial Transplant. 2009;24(10):3186-92.

3. Seyed S, Beladi M, Fatemeh $\mathrm{H}$, et al. Comparison of survival in patients with end-stage renal disease. Receiving hemodialysis versus peritoneal dialysis. Saudi J Kidney Dis Transpl. 2015;26(2):392-7.

4. An overview of regular dialysis treatment in Japan as of 31 December 2003. Patient Registration Committee, Japanese Society for Dialysis Therapy, Tokyo, Japan. et al. Ther Apher Dial. 2005.

5. Iseki K, Shinzato T, Nagura Y, Akiba T. Factors influencing long-term survival in patients on chronic dialysis. Clin Exp Nephrol. 2004;8(2):89-97.

6. Jin DC. Current status of dialysis therapy in Korea. Korean J Intern Med. 2011;26:123-31.

7. Ansell D, Roderick P, Hodsman A, Ford D, Steenkamp R, Tomson C. UK Renal Registry 11th Annual Report (December 2008): Chapter 7 survival and causes of death of UK adult patients on renal replacement therapy in 2007: national and centre-specific analyses. Nephron Clin Pract. 2009;111 Suppl 1: c113-39.

8. Wolfe RA. The standardized mortality ratio revisited; improvements, innovations. Am J Kidney Dis. 1994;24:290-7. 
9. Wolfe RA, Sheraon TE, Ashby VB, Messana JM. Decreases in catheter uses are associated with decreases in mortality for dialysis facilities during 200003. Abstract Renal Week 2005, SA-FC063

10. Choi J-Y, Jang HM, Jongha P, et al. Survival Advantage of Peritoneal Dialysis Relative to Hemodialysis in the Early Period of Incident Dialysis Patients: A Nationwide Prospective Propensity- Matched Study in Korea. PLoS One. 2013;8(12):e84257. doi:10.1371/journal.pone.0084257. eCollection 2013.

11. Browne $\mathrm{OT}$, Allgar $\mathrm{V}$, Bhandari $\mathrm{S}$. Analysis of factors predicting mortality of new patients commencing renal replacement therapy 10 years of follow-up. BMC Nephrol. 2014;15:20. doi:10.1186/1471-2369-15-20.

12. Levy J, Brown E, Daley C, Lawrence A. Death in dialysis patient. Principles of dialysis. Oxford Handbook of Dialysis. 3th Edition. Oxford University Press; 2009. pp 566-8.

13. Uchida K, Shoda J, Sugahara S, et al. Comparison and survival of patients receiving hemodialysis and peritoneal dialysis in a single center. Adv Perit Dial. 2007;23:144-17.

Submit your next manuscript to BioMed Central and we will help you at every step:

- We accept pre-submission inquiries

- Our selector tool helps you to find the most relevant journal

- We provide round the clock customer support

- Convenient online submission

- Thorough peer review

- Inclusion in PubMed and all major indexing services

- Maximum visibility for your research

Submit your manuscript at www.biomedcentral.com/submit
Biomed Central 